\title{
Comparison of hyperactivity and inattention symptoms in female adolescents with and without a history of pregnancy
}

\author{
Vania Aldrete-Cortez, ${ }^{1}$ Silvia A. Tafoya, ${ }^{2}$ Francisco Meillon, ${ }^{1}$ Adrián Poblano, ${ }^{3}$ Rodrigo Ayala-Yáñez, ${ }^{4}$ and \\ Armando Mansilla-Olivares ${ }^{5}$ \\ ${ }^{1}$ Universidad Panamericana, School of Psychology, Laboratory of Cognitive Neurosciences and Development; ${ }^{2}$ Universidad Nacional Autónoma de \\ México, Faculty of Medicine, Department of Psychiatry and Mental Health; ${ }^{3}$ Instituto Nacional de Rehabilitación, Laboratory of Cognitive \\ Neurophysiology; ${ }^{4}$ Hospital CimiGen, Medical Direction; ${ }^{5}$ Academia Nacional de Medicina de México, Ciudad de México, Mexico
}

\begin{abstract}
Introduction: Teenage pregnancy has a negative impact both on mother's health and on her offspring quality life and development. In spite of its important social relevance, behavioral factors that can favor its occurrence have not been extensively explored. Objective: To compare symptoms of inattention and hyperactivity between adolescents with and without a history of pregnancy. Method: A sociodemographic record and the attention deficit hyperactivity disorder questionnaire (ADD) of the Neuropsi instrument were applied to 60 adolescents: 30 cases and 30 controls. The ADD was answered by the adolescents themselves, as well as by a close relative (parent or spouse) or by one of their teachers. Results: From the perspective of others (parents and teachers), adolescents with a history of pregnancy showed more symptoms of attention deficit and higher attention deficit and hyperactivity overall score (both $p \leq 0.01$ ). In addition, $A D D$ overall score was found to be associated with adolescent pregnancy $(O R=1.11,95 \% \mathrm{Cl}=1.01-1.24, p=0.036)$ Conclusions: Symptoms of attention deficit and hyperactivity can represent another factor associated with teenage pregnancy.
\end{abstract}

KEY WORDS: Teenage pregnancy. ADHD. Inattention. Hyperactivity.

\section{Introduction}

Mexico has the highest teenage pregnancy rate among the countries of the Organization for Economic Cooperation and Development (64:1000). ${ }^{1}$ In the 2012 National Health Survey in Mexico City, $39.7 \%$ of women between 12 and 19 years of age who initiated sexual activity have been pregnant. ${ }^{2}$ In 2013 , there were 77 births per 1000 adolescents between 15 and 19 years of age (National Institute of Statistics and Geography, 2015). Forty percent of these pregnancies are estimated to be unwanted, ${ }^{3}$ which increases the risk of abuse and neglect in those children, ${ }^{4}$ as well as poor cognitive and emotional neurodevelopment. ${ }^{5}$ Parenting in adolescence limits opportunities because it is associated with poor physical and mental health outcomes, as well as with low levels of education and income in adulthood, ${ }^{4-7}$ which perpetuates the cycle of poverty and social vulnerability where adolescent mothers usually come from.

There are studies that address the characteristics of the social context where these pregnancies develop, which range from life within marginalized sectorswith a weak social structure and often with intrafamily violence- to separation of couples, cohabitation, alcoholism and drug addiction, just to mention a few. ${ }^{6-8}$ However, adolescents' neurobiological situations that can represent a risk factor for pregnancy at early stages of life, such as the presence of symptoms hyperactivity and attention deficit, have been little explored.

Attention-deficit/hyperactivity disorder (ADHD) is defined as a "persistent pattern of inattention and/or hyperactivity-impulsivity that interferes with functioning or development". The main symptoms are inattention,
Gac Med Mex. 2018;154:558-565

Contents available at PubMed www.gacetamedicademexico.com 
hyperactivity or impulsivity. Inattention is defined as the behavioral manifestation of not focusing, mentally wandering in activities, which leads to a lack of persistence and disorganization. Hyperactivity basically refers to excessive motor activity at inappropriate moments and impulsiveness to hasty actions, without being previously thought of and that have a high potential of harm to the individual. ${ }^{9}$

During adolescence, motor hyperactivity and impulsivity symptoms may be less obvious and be restricted to frolicking or to an inner sensation of nervousness, restlessness or impatience, little planning and impulsive decision making. ${ }^{9}$ Although many subjects with these manifestations do not meet the criteria for ADHD diagnosis, it is important for the frequency of those symptoms to be screened during said period of development because having this disorder in childhood is associated with risky sexual behavior in adult life, early onset of sexual activity, higher number of sexual partners, ${ }^{10}$ as well as with pregnancies during adolescence. ${ }^{4,11}$ Notwithstanding, the frequency of ADHD-associated symptoms apparently has not been analyzed in adolescents.

The purpose of this research was to compare the frequency of inattention and hyperactivity symptoms between adolescents without and with a history of pregnancy (control and case groups, respectively).

\section{Method}

The participants of this research were provided information about the study and both adolescents and their parents or legal guardians were asked to sign the assent or informed consent, as appropriate, in accordance with the Declaration of Helsinki. The Research Committee of the Faculty of Health Sciences of Universidad Panamericana approved the conduction of this study (protocol CIP-A-007-2017-1).

To include cases and controls in the study, they were required to be aged between 14 and 17 years, to have at least junior high-school education, normally evolving ongoing or recently concluded pregnancy (cases) and to be accompanied by a close relative and teacher at the moment of the interview. Data of those who did not fully complete the questionnaires, who had diseases that could modify behavior such as chronic or infectious diseases (e.g., epilepsy, psychosis, acquired immunodeficiency syndrome, syphilis), who were receiving medication regularly (e.g., antihypertensive, anticonvulsant, antipsychotic drugs), with congenital malformations (e.g., cleft lip and palate, microtia, amelia) or genetic diseases (e.g., Down syndrome, Turner syndrome) were censored. Similar distribution between both groups was sought; 69 teenagers were registered, out of which nine did not complete the questionnaires. Final population was composed of 30 cases and 30 controls.

The study had an observational, comparative, cross-sectional design, and it was carried out from August 2017 to March 2018 in a mother \& child hospital and in two public high schools, all three located in Mexico City. Members of the research team attended these venues and adolescent girls were invited to participate.

Regarding adolescents at the hospital (cases), since they were generally accompanied by any of their parents or couples for medical examination, the questionnaires were applied at that moment when both agreed. In this group, it was not possible for a teacher to answer the questionnaire, given that $69 \%$ of these adolescents were not attending school. Adolescents in schools (controls) were asked for assent and were given a consent letter for their parents; once they delivered it undersigned, they answered their questionnaires and in case the parents had agreed to participate themselves, they delivered the questionnaires answered by them. In addition, in this group, a teacher (who at the moment of the interview was in charge of a school course with the participants) was asked to answer a questionnaire about each teenager. Finally, all adolescents were offered psychological accompaniment free of charge.

\section{Instruments}

- Attention-Deficit/Hyperactivity (ADHD) Disorder Questionnaire of the Neuropsi instrument. It is a questionnaire based on criteria of the fourth revision of the Diagnostic and Statistical Manual of Mental Disorders to identify symptoms, as well as possible attention deficit and hyperactivity in people between 6 and 17 years of age. ${ }^{12,13}$ It consists of 9 questions to assess inattention and 9 for hyperactivity-impulsivity, which are answered using a Likert scale that goes from never to always. The child/adolescent is considered to meet the criteria for attention deficit or hyperactivity when parents and teachers answer many times and always to at least 6 questions on each part of the questionnaire. This instrument is designed to be answered by parents and/or teachers; however, in the present study the adolescents were 
also requested to answer it, in order to assess their appreciation, and therefore there were three versions: the adolescent, the companion (parents/couple) and the teacher version. For data analysis, total scores and scores by subscales were considered.

- Questionnaire of sociodemographic variables. Questions regarding years of education, occupation, income level, household characteristics, consumption of substances (tobacco, alcohol, drugs), age of onset of active sexual life, maternal characteristics, as well as those of their children.

\section{Statistical analysis}

Data were analyzed with the statistical program SPSS, version 23 , with statistical significance being determined at a $p$-value of $\leq 0.05$, with two-tailed hypothesis testing. To compare the groups of cases and controls t-tests were performed for independent samples, with data being described with means and standard deviations. When variables did not have a normal distribution - which was detected with the Shapiro-Wilk test- they were analyzed using Mann-Whitney's U-test. Qualitative variables were described with frequencies and percentages and were compared using the chi-square test.

The comparisons between control adolescents, cases with a history of pregnancy and cases with ongoing pregnancy were carried out with Kruskal-Wallis test. Finally, simple logistic regressions were performed in order to assess the association of attention deficit and hyperactivity symptoms, as well as sociodemographic variables (level of income, number of people who depend on the income, type of housing, number of siblings, place in the family, years of education and occupation), with adolescent pregnancy as a dependent variable.

\section{Results}

Sixty adolescents participated, 30 controls and 30 cases. Since the latter group was comprised by 22 adolescents who already had had children and eight who were pregnant at the time of the study, sociodemographic characteristics were compared between these subgroups, without significant differences being observed, and thus they continued to be considered as a single group (Table 1).
The comparison between cases and controls showed differences in marital status: 15 cases (50\%) were cohabitating and none of the controls was in that situation $(p=0.001)$. No significant differences were found between $16.1 \pm 0.5$ years of age of controls and $17.1 \pm$ 0.9 years of cases $(p=0.109$ ), type of housing $(p=0.347)$, economic income $(p=0.678)$ or number of people dependent on the income $(p=0.847)$. Neither were differences observed with regard to the place they occupied in the family ( $p=0.228)$, tobacco consumption $(p=0.197)$ or alcohol consumption $(p=0.117)$. As for family conformation, 29 cases (96.7\%) and 23 controls $(76 \%)$ had siblings $(p=0.001)$. About their sexual activity, 30 cases (100\%) and 6 controls $(20 \%)$ were sexually active $(p=0.001)$, with an earlier age of initiation among the control participants ( $14.5 \pm 0.84$ years) with regard to cases (15.8 \pm 1.14 years) ( $p=0.009$ ).

Among the cases, in $27(90 \%)$ the others or third party version was that of the parents or legal guardians and in $3(10 \%)$, of the companion, and of the parents or legal guardians in $30(100 \%)$ of the control group participants; in addition, the teachers' version was obtained in $30(100 \%)$ of the adolescents in the control group.

\section{Maternal and children characteristics}

Of the interviewed mothers (cases), 8 (26.7 \%) were pregnant at the moment of assessment and were at third trimester of pregnancy, and $22(73.3 \%)$ already had children; of the latter, 21 had one child (95\%) and one had two children (5\%). Twenty-six participants of this group $(86.7 \%)$ referred not having planned their pregnancy, while $8(26.7 \%)$ expressed that their child was not wanted. Since one inclusion criterion for the cases was a normally evolving pregnancy, no important ailments were reported. Both in the subgroup with a history of pregnancy and in the group with ongoing pregnancy, pregnancies were single and under obstetric control, and there was no evidence of malformations in the children or fetuses. Regarding the group with a history of pregnancy, all children were full term, with a birth weight of $3023 \pm 227 \mathrm{~g}$ (1 SD), with an average of 8.8 (3-15) examinations during pregnancy.

\section{Neuropsi Questionnaire for ADD}

When Neuropsi Questionnaire total score for ADD was compared, significant differences were observed 
Table 1. Sociodemographic characteristics comparison between adolescents with a history of pregnancy and with ongoing pregnancy

\begin{tabular}{|c|c|c|c|c|c|c|}
\hline & \multicolumn{4}{|c|}{ Cases } & \multirow[t]{2}{*}{$t, \chi^{2}, U$} & \multirow[t]{2}{*}{$p$} \\
\hline & \multicolumn{2}{|c|}{ History of pregnancy } & \multicolumn{2}{|c|}{ Ongoing pregnancy } & & \\
\hline Age $^{*}$ & \multicolumn{2}{|c|}{$17.55 \pm 1.10$} & \multicolumn{2}{|c|}{$17.38 \pm 1.77$} & 0.25 & 0.804 \\
\hline Years of education* & \multicolumn{2}{|c|}{$10.81 \pm 1.68$} & \multicolumn{2}{|c|}{$10.75 \pm 1.98$} & 0.09 & 0.926 \\
\hline \multirow[t]{2}{*}{ Active sexual life initiation* } & \multicolumn{2}{|c|}{$15.82 \pm 1.05$} & \multicolumn{2}{|c|}{$16 \pm 1.41$} & -0.38 & 0.706 \\
\hline & $\mathrm{n}$ & $\%$ & $\mathrm{n}$ & $\%$ & & \\
\hline \multicolumn{7}{|l|}{ Marital status ${ }^{\star \star}$} \\
\hline Single & 11 & 50 & 4 & 50 & \multirow[t]{2}{*}{0.00} & \multirow[t]{2}{*}{0.999} \\
\hline Married & 11 & 50 & 4 & 50 & & \\
\hline \multicolumn{7}{|l|}{ Has siblings ${ }^{\star \star}$} \\
\hline Yes & 22 & 100 & 7 & 88 & \multirow[t]{2}{*}{2.84} & \multirow[t]{2}{*}{0.267} \\
\hline No & 0 & 0 & 1 & 12 & & \\
\hline \multicolumn{7}{|l|}{ Alcohol consumption** } \\
\hline Yes & 8 & 36 & 1 & 12 & \multirow[t]{2}{*}{1.59} & \multirow[t]{2}{*}{0.207} \\
\hline No & 14 & 64 & 7 & 88 & & \\
\hline \multicolumn{7}{|l|}{ Tobacco consumption ${ }^{\star \star}$} \\
\hline Yes & 6 & 27 & 2 & 25 & \multirow[t]{2}{*}{0.01} & \multirow[t]{2}{*}{0.901} \\
\hline No & 16 & 73 & 6 & 75 & & \\
\hline \multirow{5}{*}{$\begin{array}{l}\text { Monthly economic income } \\
<10000 \\
\text { Between } 10000 \text { and } 30000 \\
>30000\end{array}$} & & & & & \multirow{4}{*}{1.09} & \multirow{4}{*}{0.580} \\
\hline & 13 & 59 & 6 & 75 & & \\
\hline & 8 & 36 & 2 & 25 & & \\
\hline & 1 & 0 & 0 & 0 & & \\
\hline & Median & P25, P75 & Median & P25, P75 & Median & P25, P75 \\
\hline $\begin{array}{l}\text { Number of people dependent } \\
\text { on income }{ }^{\ddagger}\end{array}$ & 5 & 3,5 & 5 & 4,5 & 88.00 & 0.999 \\
\hline
\end{tabular}

between cases and controls for attention deficit, hyperactivity-impulsivity and overall score in the adolescent version ( $p \leq 0.05$ for each), with higher values in the control group. On the other hand, the companion version did not show significant differences for any variable. Conversely, the comparison of symptoms in the others' version (teacher-control version versus companion-case version) showed that the group of cases had higher scores than controls in attention deficit, hyperactivity and overall score $(p \leq 0.01$ for each one) (Table 2).

In the others' version, Neuropsi ADD symptoms were compared again, dividing he group of cases into two subgroups according to the timing of pregnancy, and thus there were three groups: adolescents without a history of pregnancy (controls), cases with a history of pregnancy and cases with ongoing pregnancy. Significant differences were observed for attention deficit $(p=0.037)$, hyperactivity $(p=0.010)$ and global score $(p=0.007)$. Pairwise comparison showed significant differences between control adolescents and cases with a history of pregnancy for attention deficit $(p=0.031)$, hyperactivity $(p=0.021)$ and overall score $(p=0.006)$. Similarly, the comparison between control participants and the group of cases with ongoing pregnancy showed differences for attention deficit $(p=0.043)$, hyperactivity $(p=0.007)$ and overall score $(p=0.023)$. The comparison between the group of cases with a history of pregnancy and with ongoing pregnancy showed no differences in attention deficit $(p=0.620)$, hyperactivity $(p=0.329)$ or overall score $(p=0.452)$; however, a trend towards higher scores was observed in the ongoing pregnancy group (Fig. 1).

Finally, in order to assess adolescent pregnancy-associated variables, simple logistic regressions with were obtained (Table 3), with sociodemographic and clinical characteristics being considered as independent variables. The number of siblings, attention deficit and hyperactivity-impulsivity scores and total $\mathrm{Neu}-$ ropsi symptoms according to the others' version were observed to be associated with pregnancy. 
Table 2. Neuropsi ADHD Questionnaire total scores comparing the adolescent, companion and others versions, divided by cases and controls

\begin{tabular}{|c|c|c|c|c|c|c|c|c|c|}
\hline \multirow[t]{3}{*}{ Neuropsi } & \multicolumn{9}{|c|}{ Versions } \\
\hline & \multicolumn{2}{|c|}{ Adolescent } & \multirow[t]{2}{*}{$\mathbf{U}$} & \multicolumn{2}{|c|}{ Companion } & \multirow[t]{2}{*}{$\mathbf{U}$} & \multicolumn{2}{|c|}{ Others $^{\ddagger}$} & \multirow[t]{2}{*}{$\mathbf{U}$} \\
\hline & Cases & Controls & & Cases & Controls & & $\begin{array}{c}\text { Cases } \\
\text { (companion) }\end{array}$ & $\begin{array}{l}\text { Controls } \\
\text { (teacher) }\end{array}$ & \\
\hline$A D$ & $3.67(3.44)$ & $\begin{array}{c}6.10 \\
(4.54)\end{array}$ & $-2.28^{*}$ & $\begin{array}{c}4.23 \\
(4.95)\end{array}$ & $\begin{array}{c}4.77 \\
(4.21)\end{array}$ & -1.09 & $\begin{array}{c}4.77 \\
(4.21)\end{array}$ & $\begin{array}{c}1.93 \\
(2.80)\end{array}$ & $-2.52^{\star \star}$ \\
\hline $\mathrm{H}-\mathrm{I}$ & $3.33(3.60)$ & $\begin{array}{c}5.53 \\
(5.16)\end{array}$ & $-1.95^{\star}$ & $\begin{array}{c}3.36 \\
(4.11)\end{array}$ & $\begin{array}{c}3.87 \\
(4.35)\end{array}$ & -0.69 & $\begin{array}{c}3.87 \\
(4.35)\end{array}$ & $\begin{array}{c}1.34 \\
(2.74)\end{array}$ & $-2.86^{\star \star}$ \\
\hline Total & $7.00(6.50)$ & $11.63(8.95)$ & $-2.24^{*}$ & $\begin{array}{l}7.80 \\
(8.62)\end{array}$ & $\begin{array}{c}8.63 \\
(7.35)\end{array}$ & -0.90 & $\begin{array}{c}8.63 \\
(7.35)\end{array}$ & $\begin{array}{c}3.27 \\
(5.31)\end{array}$ & $-3.10^{* *}$ \\
\hline
\end{tabular}

The means refer to the average of the direct scores that were reached in different areas of the test. $A D=$ attention deficit, $\mathrm{H}-\mathrm{I}=$ hyperactivity-impulsivity.

FIn the case of the others, the companion version was compared in the cases, and the teacher version in the controls. Comparisons were carried out using Mann-Whitney's U-test, ${ }^{*} \mathrm{p} \leq 0.05$, ${ }^{* *} p \leq 0.01$.
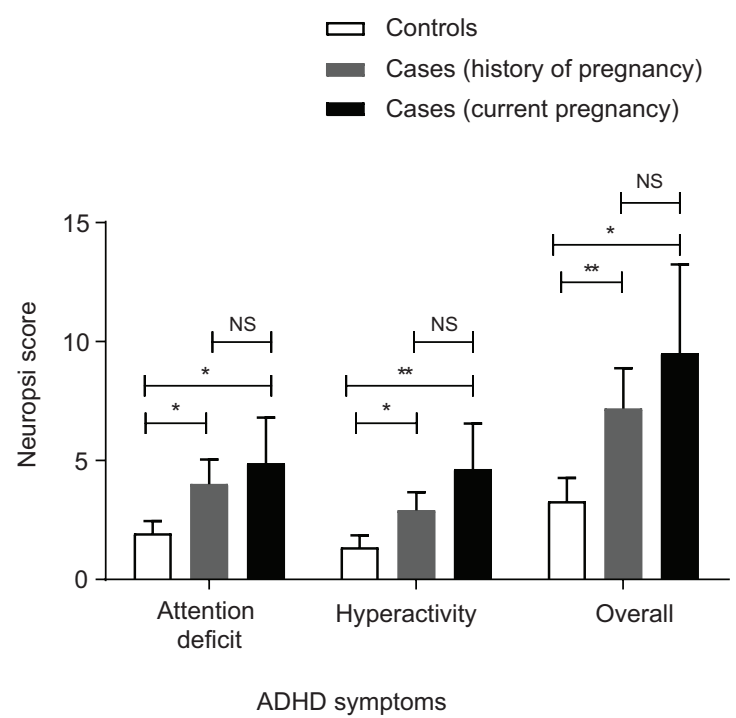

Figure 1. Comparison of the others' version (parents/legal guardians and teacher) with regard to the Neuropsi ADD Questionnaire ADHD symptoms. The graphs represent averages and standard errors for each scale. $A D=$ attention deficit, $H-I=$ hyperactivity-impulsivity. Pairwise comparisons were made by means of Mann-Whitney's U-test. ${ }^{*} p \leq 0.05,{ }^{* *} p \leq 0.01, N S=$ not significant.

\section{Discussion}

The purpose of this study was to compare attention deficit and hyperactivity symptoms in adolescents with and without a history of pregnancy, with the hypothesis that the group with a history of pregnancy would have more symptoms, which was partially accepted, since the comparison of the scores from the others' version showed that adolescents with a history of pregnancy had more attention deficit and hyperactivity symptoms than controls. To the best of our knowledge, this is the first study to evaluate ADHD symptoms in adolescent mothers, which might have implications in adolescent pregnancy prevention programs.

ADHD (attention deficit/hyperactivity deficit)-related symptoms have been associated with risky sexual behaviors and early or unintended pregnancy., ${ }^{4,11,14}$ When children diagnosed with ADHD, ${ }^{4}$ with ADHD-associated symptoms, ${ }^{11}$ hyperactivity and aggression problems ${ }^{15}$ and attention deficit, hyperactivity and behavior problems ${ }^{16}$ have been followed-up, they have been observed to show an increased risk of pregnancy in adolescence. In fact, Meinzer et al. reported that those with such difficulties experience more adolescent pregnancies $(9.3 \%)$ than the control group (4.3\%), which constitutes a two-fold higher risk of adolescent pregnancy $(O R=2.08)$.

Most studies are based on follow-up and give importance to ADHD diagnosis in childhood as a risk factor for adolescent pregnancy. ${ }^{4,11,15,16}$ However, few analyses have evaluated ADHD-associated symptoms during adolescence and their relationship with pregnancy, and those that exist are case studies. ${ }^{17}$ Research on ADHD evolution of during adolescence is still missing ${ }_{18}^{18}$ and hence this study contributes to the knowledge on ADHD in females during adolescence.

ADHD symptoms have been proposed in the literature to persist in adolescence and adulthood in 15 to $65 \%$ of subjects. ${ }^{14,18}$ Difficulties in adolescence remain in spite of symptom reduction and, thus, on numerous occasions adolescents do not meet the criteria for ADHD diagnosis. ${ }^{18}$

In our results, more attention deficit than hyperactivity symptoms were observed, which is consistent with the literature, which refers that motor activity 
Table 3. Bivariate analysis of factors associated with adolescent pregnancy

\begin{tabular}{llcl}
\hline & OR & 95\% confidence interval & $\mathbf{p}$ \\
\hline Level of income & 0.68 & $0.28-1.62$ & 0.383 \\
Number of people depending on the income & 1.15 & $0.83-1.60$ & 0.386 \\
Number of siblings & 8.83 & $1.01-76.96$ & 0.049 \\
Type of household & 1.81 & $0.52-6.38$ & 0.351 \\
Place in the family & 0.73 & $0.40-1.33$ & 0.306 \\
Years of education & 1.34 & $0.88-2.05$ & 0.168 \\
Occupation & 0.22 & $0.02-2.13$ & 0.194 \\
Attention deficit symptoms, others' version & 1.18 & $1.01-1.41$ & 0.050 \\
Hyperactivity-impulsivity symptoms, others' version & 1.22 & $1.01-1.50$ & 0.052 \\
Total symptoms, others' version & 1.11 & $1.01-1.24$ & 0.036 \\
\hline
\end{tabular}

decreases and an internal feeling of restlessness, agitation and lack of attention emerges as the main problem, ${ }^{14,19}$ as well as self-regulation and executive function problems. ${ }^{14,20}$ This alters daily-life functioning and can result in unintended pregnancy during adolescence and decreased awareness or reflection regarding its difficulties. The latter is observed in the adolescents' version results, where the cases reported fewer symptoms than the control group, which we assume agrees with the idea that this group finds it difficult to realize their problems. Such alterations are associated with executive dysfunction, a feature that has been widely associated with ADHD symptoms. Executive dysfunction includes difficulties to solve problems, inhibit impulses, select the stimulus, discard the distractor stimulus, hierarchically organize stimuli, target a goal and in self-regulation. ${ }^{14,20}$

Similarly, in the companion version, no significant differences were observed between groups, i.e., the parents or companion did not distinguish the presence of attention deficit/hyperactivity symptoms between the groups with and without a pregnancy history. In this regard, it has been pointed out that one of the difficulties in symptom identification can be attributed to their evolution over time, since from childhood to adolescence not only are they transformed in their expression but they also show a decrease, which is more pronounced in hyperactivity and impulsivity associated-symptoms, which are the most evident. ${ }^{21}$

To assess whether the presence of ongoing pregnancy could bias the results, ADHD symptoms comparisons were made between the groups with no history of pregnancy, with a history of pregnancy and with ongoing pregnancy. Differences were found only in the comparison of the group without a history of pregnancy (control) when contrasted with the cases with a history of and with ongoing pregnancy, i.e., ADHD symptoms between adolescents with ongoing pregnancy and with a history of pregnancy were statistically equal. However, a trend towards higher scores was observed in the group of adolescents with ongoing pregnancy. This might be explained by the biological modifications that accompany pregnancy, such as cerebral and cognitive changes, where a transient reduction of gray matter volume has been reported in the central nervous system, ${ }^{22}$ as well more permeable brain tissue,$^{23}$ increase in the density of dendritic spines in the dentate gyrus ${ }^{24}$ and in bilateral hippocampal connectivity, ${ }^{23}$ as well as changes in cognitive performance, with a subtle deterioration in information processing speed and in some memory tasks being observed during pregnancy, due to the cost of cognitive reorganization, which favors parenthood-related processes such as social cognition, recognition of faces and emotions, as well as processes that mitigate reactivity to stress. ${ }^{25}$

The cognitive profile associated with brain changes during pregnancy and that includes social demands during motherhood, which also influence on the caregiver's brain remodeling, remains to be established. ${ }^{22,26}$ However, there are no investigations that have analyzed the response pattern of pregnant women in tasks that assess different types of attention, even less so in tasks that are associated with symptoms of hyperactivity in adolescent females. 
For these reasons, it is important for the attention and hyperactivity-related characteristics in adolescents with ongoing pregnancy and in those who already had children to be differentiated. Future investigations might analyze these processes with data prior to pregnancy and with neuropsychological and experimental evaluations that detail performance in these processes.

On the other hand, there are various studies that have associated adolescent pregnancy with social factors such as lower level of education of the adolescent, ${ }^{27,28}$ economic disadvantage, ${ }^{6,29}$ school dropout, ${ }^{30}$ sexual activity initiation at age 15 or younger, being unemployed, parental lower level of education, ${ }^{31}$ and risky behaviors such as alcoholism and smoking. ${ }^{29}$ In our study, only the number of siblings was found to be a risk factor for adolescent pregnancy; the other social variables were not significant. This aspect might be explained from different perspectives: from the number of children parents can look after, to the assumption that at least one of the parents of children with ADHD may also suffer from it and therefore neglect their children, ${ }^{14,32}$ i.e., it is possible that any of the interviewed parents from the group of cases has the same difficulties as their daughters, This way, adults with $A D H D$ can raise children with lack of consistency, be unpredictable, impulsive, fail to listen and to be sensitive to the other; they can be disorganized, with temperamental tendencies related to the search for novelty, extroversion or taste for intense activities. All this makes cohabitation with the couple difficult, and a vicious circle is generated with the problems they have with their children, ${ }^{14,33}$ which produces more vulnerable family structures, whereby the risk of adolescent pregnancy increases. ${ }^{11}$

This way, attention deficit and hyperactivity symptoms were also found to be significantly associated with adolescent pregnancy, behaving as a risk for early pregnancy. However, both the variable related to social context, such as the number of siblings, and the neurobiological variable measured in this study (frequency of symptoms associated with hyperactivity and inattention during pregnancy in adolescence) showed a low value as to explain the dependent variable, although said value was significant.

One limitation of this study is that only the association of ADHD symptoms with pregnancy was sought, and including a population with this diagnosis for future analyses could therefore be considered. It should be highlighted that, as far as we know, this is the first study to associate ADHD symptoms during adolescence with pregnancy, which helps to know more about ADHD evolution in females during this period. In addition, carrying out multicenter studies that can generate epidemiological data about this phenomenon is suggested for future investigations.

\section{Conclusions}

The frequency of hyperactivity and inattention symptoms was observed to be higher in adolescents with a history of pregnancy, which suggests that girls with ADHD-associated symptoms might have a higher risk of pregnancy when they reach puberty. Since adolescent pregnancy is a rather complex phenomenon, a broader understanding is required that integrates neurobiological and social variables, given the impact this phenomenon has on the adolescent mother and in her children.

\section{Acknowledgements}

To Dr. Paulina Langrave and to Guadalupe Herrera Fernández and Guadalupe Morales Ramírez, for their support to carry out this study, as well as to Conacyt-SNI, for the support with the 65590 and 73097 grants.

\section{References}

1. Salceda M, Aparicio N. Informar y sensibilizar sobre temas que afectan a las adolescentes en México SCA y UNICEF se unen en una campaña nacional. México: United Nations International Children's Emergency Fund; 2016.

2. Gutiérrez J, Rivera-Dommarco J, Shamah-Levy T, Oropeza C, Hernández-Ávila M (coordinadores). Encuesta Nacional de Salud y Nutrición 2012. Resultados Nacionales. Cuernavaca. México: Instituto Nacional de Salud Pública; 2012.

3. Zúñiga $E$, Delgado D, Zubieta B. Tendencias recientes del embarazo adolescente en México. En: Foro embarazo en adolescentes: avances y retos. México: Comisión Nacional de la Mujer; 2000.

4. Meinzer MC, LeMoine KA, Howard AL, Stehli A, Arnold LE, Hechtman L, et al. Childhood ADHD and involvement in early pregnancy: mechanisms of risk. J Atten Disord. 2017:1087054717730610.

5. Aldrete-Cortez V, Carrillo-Mora P, Mansilla-Olivares A, Schnaas L, Esquivel-Ancona F. From emotional and cognitive regulation to self-regulation development in the first year of life. An Psicol/UB J Psychol. 2014; 44:199-212.

6. Boden JM, Fergusson DM, John Horwood L. Early motherhood and subsequent life outcomes. J Child Psychol Psychiatry. 2008;49:151-160.

7. Sámano R, Martínez-Rojano H, Robichaux D, Rodriguez-Ventura AL, Sánchez-Jiménez B, De la Luz Hoyuela M, et al. Family context and individual situation of teens before, during and after pregnancy in Mexico City. BMC Pregnancy Childbirth. 2017;17:382.

8. Stern C. Vulnerabilidad social y embarazo adolescente en México. Pap Poblac. 2004;10:129-158.

9. Diagnostic and Statistical Manual of Mental Disorders (DSM-5). EE. UU.: American Psychiatric Publishing; 2013.

10. Flory K, Molina BS, Pelham WE, Gnagy E, Smith B. Childhood ADHD predicts risky sexual behavior in young adulthood. J Clin Child Adolesc Psychol. 2006;35:571-577.

11. Lehti V, Niemelä S, Heinze M, Sillanmäki L, Helenius H, Piha J, et al. Childhood predictors of becoming a teenage mother among Finnish girls. Acta Obstet Gynecol Scand. 2012;91:1319-1325.

12. DSM-IV: Manual diagnóstico y estadístico de los trastornos mentales. España: American Psychiatric Association; 2002. 
13. Ostrosky-Solís F, Esther Gómez-Pérez M, Matute E, Rosselli M, Ardila A Pineda D. NEUROPSI attention and memory: a neuropsychological test battery in Spanish with norms by age and educational level. Appl Neuropsychol. 2007;14:156-170.

14. Trott GE. Attention-deficit/hyperactivity disorder (ADHD) in the course of life. Eur Arch Psychiatry Clin Neurosci. 2006;256:i21-i25.

15. Fontaine N, Carbonneau R, Barker ED, Vitaro F, Hébert M, Coté SM et al. Girls' hyperactivity and physical aggression during childhood and adjustment problems in early adulthood: a 15-year longitudinal study. Arch Gen Psychiatry. 2008;65:320-328.

16. Woodward LJ, Fergusson DM. Early conduct problems and later risk of teenage pregnancy in girls. Dev Psychopathol. 1999;11:127-141.

17. Lyman D. Possible link between attention-deficit/hyperactivity disorder and reproductive complications. Prim Care Companion J Clin Psychiatry. 2002;4:104-108.

18. Young S, Adamou M, Asherson P, Coghill D, Colley B, Gudjonsson G, et al. Recommendations for the transition of patients with ADHD from child to adult healthcare services: a consensus statement from the UK adult ADHD network. BMC Psychiatry. 2016;16:301.

19. Vásquez J, Cárdenas EM, Feria M, Benjet C, Palacios L, De-La-Peña F. Guía clínica para el trastorno por déficit de atención e hiperactividad. México: Instituto Nacional de Psiquiatría Ramón de la Fuente Muñiz; 2010.

20. Schoenfelder EN, Kollins SH. Topical review: ADHD and health-risk behaviors: toward prevention and health promotion. J Pediatr Psychol. 2016;41:735-740.

21. Pingault JB, Viding E, Galéra C, Greven CU, Zheng Y, Plomin R, et al. Genetic and environmental influences on the developmental course of attention-deficit/hyperactivity disorder symptoms from childhood to adolescence. JAMA Psychiatry. 2015;72:651-658.

22. Luders E, Gingnell M, Poromaa IS, Engman J, Kurth F, Gaser C. Potential brain age reversal after pregnancy: younger brains at 4-6weeks postpartum. Neuroscience. 2018;386:309-314.
23. Chan RW, Ho LC, Zhou IY, Gao PP, Chan KC, Wu EX. Structural and functional brain remodeling during pregnancy with diffusion tensor MRI and resting-state functional MRI. PloS One. 2015;10:e0144328.

24. ljomone OK, Shallie $P$, Naicker T. Changes in the structure and function of the brain years after pre-eclampsia. Ageing Res Rev. 2018;47:49-54.

25. Anderson MV, Rutherford MD. Cognitive reorganization during pregnancy and the postpartum period: an evolutionary perspective. Evol Psychol. 2012;10:659-687.

26. Rangel JL, Valerio L, Patiño J, García M. Funcionalidad familiar en la adolescente embarazada. Rev Fac Med UNAM. 2004;47:24-27.

27. Hofferth SL, Reid L, Mott FL. The effects of early childbearing on schooling over time. Fam Plann Perspect. 2001;33:259-267.

28. Villalobos-Hernández A, Campero L, Suárez-López L, Atienzo EE, Estrada F, De-La-Vara-Salazar E. Embarazo adolescente y rezago educativo: análisis de una encuesta nacional en México. Salud Publica Mex. 2015;57:135-143.

29. Gaudie J, Mitrou F, Lawrence D, Stanley FJ, Silburn SR, Zubrick SR. Antecedents of teenage pregnancy from a 14-year follow-up study using data linkage. BMC Public Health. 2010;10:63.

30. Payares C. Embarazo y deserción escolar. Al día con las noticias: Monitoreo de prensa. 2015 Apr 12; Sec. Opinión. Disponible en: https://www. mineducacion.gov.co/observatorio/1722/article-297667.html

31. Sánchez-Valencia YA, Mendoza-Tascón LA, Grisales-López MB, Ceballos-Molina LY, Bustamente-Farfan JC, Chaverra LA, et al. Características poblacionales y factores asociados a embarazo en mujeres adolescentes de Tuluá, Colombia. Rev Chil Obstet Ginecol. 2013;78:269-281.

32. Anselmi L, Menezes AM, Barros FC, Hallal PC, Araújo CL, Domingues MR, et al. Early determinants of attention and hyperactivity problems in adolescents: the 11-year follow-up of the 1993 Pelotas (Brazil) birth cohort study. Cad Saude Publica. 2010;26:1954-1962.

33. Park H, Suh BS, Lee HK, Lee K. Temperament and characteristics related to attention deficit/hyperactivity disorder symptoms. Compr Psychiatry. 2016;70:112-117. 